\title{
THE LINEAR PROGRAMMING APPROACH ON A-P SUPER-EFFICIENCY DATA ENVELOPMENT ANALYSIS MODEL OF INFEASIBILITY OF SOLVING MODEL
}

\author{
${ }^{1}$ Chiao-Ping Bao, ${ }^{2}$ Chen-Hu Jeng, ${ }^{1}$ Ching-Chung Guey and ${ }^{2}$ Chien-Liang Lin \\ ${ }^{1}$ Department of Industrial Management, I-Shou University, \\ No.1, Sec. 1, Xuecheng Rd., Dashu Dist., Kaohsiung City 840, R.O.C., Taiwan \\ ${ }^{2}$ Institute of Engineering Science and Technology, \\ National Kaohsiung First University of Science and Technology, \\ No.1, University Road, Yenchao, Kaohsiung 824, R.O.C., Taiwan
}

Received 2013-10-02; Revised 2013-10-15; Accepted 2014-02-03

\begin{abstract}
The traditional CCR or BCC model in DEA for DMU assessment often come out with multiple efficiency units, which cause problems in rank ordering. Therefore, we intended to improve level of discrimination among Decision Making Units (DMUs). The present study thus seeks to solve the above-mentioned problems of discrimination and infeasible solutions in A-P super-efficient mode by proposing a feasible linear programming approach. In addition, for the nonlinear problem, using $(1-\alpha) /(1+\beta)$, in the objective function and constrains of the general model when applying SE in DEA, an improved linear programming solution mode is proposed, along with the assessment model of dominated decision making units to solve the problem of infeasible solution. Through the results of proof and calculation on the data in the given example, the present study proposes linear programming solution mode suitable for input-oriented, output-oriented and nonoriented model, respectively and such a linear programming solution model can substantially improve and solve the above mentioned problems of discrimination and infeasible solutions.
\end{abstract}

Keywords: Data Envelopment Analysis (DEA), Super-Efficiency (SE), Infeasibility

\section{INTRODUCTION}

Data Envelopment Analysis (DEA) was first employed by Charnes et al. (1978) to evaluate the efficiency among Decision Making Units (DMUs) through a linear programming model. DEA features its capability of processing multiple input and output variables simultaneously. Nevertheless, such a superior mode, when in the early stage of development, will often come with the problem that more than one DMU are considered efficiency unit, thus resulting in a lack of discrimination on efficiency evaluation. In view of this Andersen and Petersen (1993) then proposed the A-P Super Efficiency Model (SE model), which greatly helps enhance the discrimination of efficiency evaluation. The essence of A-P model lies in the fact that the data of a certain DMU, while being evaluated, is not included in the efficiency frontier and the efficiency values of certain DMU are often greater than "1", which is how the term "super efficiency" is derived.

A-P model is not only originally employed to reorder the efficiency of DMU (Andersen and Petersen, 1993; Xue and Hurker, 2002; Chen, 2005; Ray, 2008; Pan et al., 2011; Ebadi, 2012), but it is also used to detect the "outlier point" (Banker and Chang, 2005). Moreover, there are discussions on the sensitivity analysis as well as stability radius (Charnes et al., 1992; Zhu, 1996; 2001; Seiford and Zhu, 1998; Leopold, 2003).

Corresponding Author: Chen-Hu Jeng, Institute of Engineering Science and Technology, National Kaohsiung First University of Science and Technology, No.1, University Road, Yenchao, Kaohsiung 824, R.O.C., Taiwan 
Thrall (1996) points out that the A-P Super Efficiency (SE) mode under Constant Returns to Scale (CCR) often results in problems of infeasible solution. Zhu (1996) proves that SE and CCR mode is the sufficient condition of infeasible solution when the values of some of the data in the input or output variable are " 0 ". In addition, even if the data values are not "O", as in other modes of the SE and the DEA, infeasible solution will also appear. Seiford and Zhu (1999) also put forward the necessary and sufficient conditions of infeasible solution in the SE model of DEA for input oriented and output-oriented situations. When applying SE in DEA, Cheng et al. (2011) proved that when any output values in $\mathrm{DMU}_{\mathrm{k}}, \mathrm{y}_{\mathrm{rk}}>\mathrm{y}_{\mathrm{rj}}, \mathrm{j}=$ $1, \ldots, \mathrm{n}, \mathrm{j} \neq \mathrm{k}$, under VRS conditions, an infeasible solution will appear in A-P super-efficient model. To solve the shortcoming of the A-P, Cheng et al. (2011), without being confined to any oriented model, adopt $(1-\alpha) /(1+\beta)$ as the objective function and add some nonlinear formula to the constrains of the general model in order to solve the problem of infeasible solution. Though their discussions are comprehensive, their proposed model is filled with nonlinear mode, making the computation of efficiency evaluation complicated.

Based on the above analysis, the purpose of the study is to propose an improved linear programming model, based on the spirits of Cheng et al. (2011), to solve the problem of infeasible solution in SE of DEA. This study consists of five sections: (1) introduction (background description of research questions), (2) A-P mode and the mode proposed by Cheng et al. (2011), (3) SE-BCC model (as proposed by the present study, with the elaboration of solution feasibility with the aid of a theorem), (4) illustration by examples and proofs of such a model with its application and (5) conclusion.

\section{MATERIALS AND METHODS}

A-P Mode and the Mode Proposed by Cheng et al. (2011): (1) Input Oriented Mode-BCC Model:

Min. $\theta$

s.t. $\sum \lambda_{\mathrm{j}} \mathrm{X}_{\mathrm{ij}} \leqq \theta \mathrm{X}_{\mathrm{ik}}, \mathrm{j} \neq \mathrm{k}, \mathrm{i}=1, \ldots, \mathrm{m}$

$\sum \lambda_{\mathrm{j}} \mathrm{y}_{\mathrm{rj}} \geqq \mathrm{y}_{\mathrm{rk}}, \mathrm{r}=1, \ldots, \mathrm{s}$

$\sum \lambda_{j}=1, \lambda_{j} \geqq 0, j=1, . ., n$

Cheng et al. (2011) proved that when applying A-P super efficiency mode of Equation (1), among all the output variables of $\mathrm{DMU}_{\mathrm{k}}$, if there is at least one $\mathrm{y}_{\mathrm{rk}}, \mathrm{r}=$ $1, \ldots, \mathrm{s}$ which is greater than the $\mathrm{y}_{\mathrm{rj}}$ of any other $\mathrm{DMU}_{\mathrm{k}}$, then there is no feasible solution in Equation (1).

\subsection{Output Oriented Mode-BCC Model}

$\operatorname{Max} . \varphi$

s.t. $\sum \lambda_{\mathrm{j}} \mathrm{X}_{\mathrm{ij}} \leqq \theta \mathrm{X}_{\mathrm{ik}}, \mathrm{j} \neq \mathrm{k}, \mathrm{i}=1, \ldots, \mathrm{m}$

$\sum \lambda_{\mathrm{j}} \mathrm{y}_{\mathrm{rj}} \geqq \varphi \mathrm{y}_{\mathrm{rk}}, \mathrm{r}=1, \ldots, \mathrm{s}$

$\sum \lambda_{j}=1, \lambda_{j} \geqq 0, j=1, . ., n$

Cheng et al. (2011) proved that when applying A-P super efficiency mode of Equation (2), among all the output variables of $\mathrm{DMU}_{\mathrm{k}}$, if there is at least one $\mathrm{y}_{\mathrm{rk}}, \mathrm{r}=$ $1, \ldots, \mathrm{s}$ which is smaller than the $\mathrm{y}_{\mathrm{rj}}$ of any other DMUk, then there is no feasible solution in Equation (2).

\subsection{Non-Oriented Mode}

To summarize the above conditions where there is no feasible solution in Equation (1) and (2), Cheng et al. (2011) proposed a non-oriented mode using Equation (2) to solve infeasible solution in Equation (1) and (2):

$$
\begin{aligned}
& \operatorname{Min}(1-\alpha) /(1+\beta) \\
& \text { s.t. } \sum \lambda_{j} X_{i j} \leqq(1+\beta) X_{i k}, j \neq k, i=1, \ldots, m \\
& \sum \lambda_{j} y_{r j} \geqq(1-\alpha) y_{r k}, r=1, \ldots, s \\
& \sum \lambda_{j}=1, \lambda_{j} \geqq 0, j=1, . ., n
\end{aligned}
$$

From the perspectives of the present study, the shortcomings of the improved mode by Cheng et al. (2011) include:

- The input-oriented and output-oriented models with certain functions were all excluded and were revised as Non-oriented Mode, which will somehow lose the spirit of DEA mode

- The non-oriented Mode in Equation (3) in its objective and constrains formula has become nonlinear programming, which causes difficulties in computation when solving the Equation

Based on the above mentioned shortcomings of SEBCC mode, the present study thus proposes the following modes.

\subsection{Input-Oriented Mode-BCC Model}

In the formula (1), if the output values in $\mathrm{DMU}_{\mathrm{k}}$ are multiplied by a "shrinking factor, (1- $\alpha)$ " in advance and make it a necessary condition, then the efficiency value of the given $\mathrm{DMU}_{\mathrm{k}}$ can be acquired under the least $\alpha+\theta$ in the objective formula. The model after revision of Equation (1) is: 
$\operatorname{Min} \theta+\alpha$

s.t. $\sum \lambda_{j} X_{i j} \leqq \theta X_{i k}, j=1, \ldots, n, j \neq k, i=1, \ldots, m$

$\sum \lambda_{\mathrm{j}} \mathrm{y}_{\mathrm{rj}} \geqq(1-\alpha) \mathrm{y}_{\mathrm{rk}}, \mathrm{r}=1, \ldots, \mathrm{s}$

$\sum \lambda_{\mathrm{j}}=1, \lambda_{\mathrm{j}} \geqq 0, \mathrm{j}=1, . ., \mathrm{n}$

In Equation (4), the purpose of adding " $\alpha$ " is to minimize " $\alpha$ " and the acquired " $\theta$ " value is not the true efficiency value " $\theta *$ " of $\mathrm{DMU}_{\mathrm{k}}$. The value of $\theta^{*}$ should be $(\theta /(1-\alpha))$.

\section{Proof:}

The true value of " $\theta *$ " in $D^{2} M_{k}=\left(\Sigma \mathrm{u}_{\mathrm{r}} \mathrm{y}_{\mathrm{rk}} / \Sigma \mathrm{v}_{\mathrm{i}} \mathrm{X}_{\mathrm{ik}}\right)=$ $\left(\Sigma-\left(\mathrm{u}_{\mathrm{r}}(1-\alpha) \mathrm{y}_{\mathrm{rk}} / \Sigma\left(\mathrm{v}_{\mathrm{i}}(1-\alpha) \mathrm{X}_{\mathrm{ik}}\right)=\theta /(1-\alpha) \neq\right.\right.$

\subsection{Output-Oriented Mode-Bcc Model}

\section{$\operatorname{Max} \varphi-\beta$}

s.t. $\sum \lambda_{\mathrm{j}} \mathrm{X}_{\mathrm{ij}} \leqq(1+\beta) \mathrm{x}_{\mathrm{ik}}, \mathrm{j} \neq \mathrm{k}, \mathrm{i}=1, \ldots, \mathrm{m}$

$\sum \lambda_{\mathrm{j}} \mathrm{y}_{\mathrm{rj}} \geqq \varphi \mathrm{y}_{\mathrm{rk}}, \mathrm{r}=1, \ldots, \mathrm{s}$

$\sum \lambda_{j}=1, \lambda_{j} \geqq 0, j=1, \ldots, n$

In Equation (5), the purpose of subtracting " $\beta$ " in the objective formula is to minimize " $\beta$ " and the acquired " $\beta$ " value is not the true efficiency value $\theta^{*}=1 / \varphi$ of DMUk. The value of " $\theta *$ should be $((1+\beta) / \varphi))$. Its proof is similar to that in Equation (4), thus omitted here.

\subsection{Non-Oriented Model}

$$
\begin{aligned}
& \text { Min. } \alpha+\beta \\
& \text { s.t. } \sum \lambda_{j} X_{i j} \leqq(1+\beta) X_{i k}, j \neq k, i=1, \ldots, m \\
& \sum \lambda_{j} y_{r j} \geqq(1-\alpha) y_{r k}, r=1, \ldots, s \\
& \sum \lambda_{j}=1, j \neq k, \lambda_{j} \geqq 0, j=1, \ldots, n
\end{aligned}
$$

Note that the objective formula of Equation (3) in the study of Cheng et al. (2011) is non-linear, but its function is similar to that of Equation (6) in the present study. If we put the results of Equation (6) in the objective formula of Equation (3), with other necessary conditions being constant, then the results of these two approaches should be the same, but the mode suggested by the present study is more feasible. $\theta^{*}=(1+\beta) /(1-\alpha)$.

\section{RESULTS}

An Illustration: Assume that there are 5 DMUs with 2 input variables and 2 output variables, data of which are specified below.

\subsection{Input-Oriented Mode-BCC Mode}

Since $y_{1}$ is greater than the first output variable of all the DMU, DMUa in the given example is chosen and we put the data of Table 1 into Equation (1), then:

$$
\begin{aligned}
& \operatorname{Min} \theta+\alpha \\
& \text { s.t. } 23 * \lambda_{2}+26 * \lambda_{3}+36 * \lambda_{4}+18 * \lambda_{5}<31 * \theta \\
& 34 * \lambda_{2}+45 * \lambda_{3}+61 * \lambda_{4}+76 * \lambda_{5}<42 * \theta \\
& 42 * \lambda_{2}+32 * \lambda_{3}+66 * \lambda_{4}+43 * \lambda_{5}<74 * \alpha>74 \\
& 25 * \lambda_{2}+65 * \lambda_{3}+35 * \lambda_{4}+55 * \lambda_{5}+55 * \alpha>55 \\
& \lambda_{2}+\lambda_{3}+\lambda_{4}+\lambda_{5}=1
\end{aligned}
$$

The optimal solution to Equation (7) is: $\theta=0.8438, \alpha$ $=0.4501$ 。 $\theta^{*}=0.8438 /(1-0.4501)=1.5345$.

\subsection{Output-Oriented Mode-BCC Mode}

Though $\mathrm{x}_{1}, \mathrm{x}_{2}$ in DMUa are not smaller than the first and second input variables of all the DMU, we still choose DMUa as an example for explanation and put the data of Table 1 into Equation (2), then:

$$
\begin{aligned}
& \operatorname{Max} \Phi-\beta \\
& \text { s.t. } 23 * \lambda_{2}+26 * \lambda_{3}+36 * \lambda_{4}+18 * \lambda_{5}-31 * \beta<31 \\
& 34 * \lambda_{2}+45 * \lambda_{3}+61 * \lambda_{4}+76 * \lambda_{5}-42 * \beta<42 \\
& 42 * \lambda_{2}+32 * \lambda_{3}+66 * \lambda_{4}+43 * \lambda_{5}>74 * \Phi \\
& 25 * \lambda_{2}+65 * \lambda_{3}+35 * \lambda_{4}+55 * \lambda_{5}>55 * \Phi \\
& \lambda_{2}+\lambda_{3}+\lambda_{4}+\lambda_{5}=1
\end{aligned}
$$

The optimal solution to Equation (8) is: $\Phi=0.6226$, $\beta=0 . \theta^{*}=1 / 0.6226=1.6062$. Owing to the $x_{1}$ and $x_{2}$ of the $\mathrm{DMU}_{\mathrm{a}}$ has not less than all DMUs' first and second term of input variables. Since the optimal solution to Equation (8), $\beta=0$, the model used in the present study does not distort the meaning of the original mode.

\subsection{Non-Oriented Model}

We still choose $\mathrm{DMU}_{\mathrm{a}}$ as an example and put the data of Table 1 into Equation (3), then:

$$
\begin{aligned}
& \text { Min. } \alpha+\beta \\
& \text { s.t. } 23 * \lambda_{2}+26 * \lambda_{3}+36 * \lambda_{4}+18 * \lambda_{5}-31 * \theta * \beta<31 \\
& 34 * \lambda_{2}+45 * \lambda_{3}+61 * \lambda_{4}+76 * \lambda_{5}-42 * \theta * \beta<42 \\
& 42 * \lambda_{2}+32 * \lambda_{3}+66 * \lambda_{4}+43 * \lambda_{5}>74 * \alpha>74 \\
& 25 * \lambda_{2}+65 * \lambda_{3}+35 * \lambda_{4}+55 * \lambda_{5}>55 * \alpha>55 \\
& \lambda_{2}+\lambda_{3}+\lambda_{4}+\lambda_{5}=1
\end{aligned}
$$


Table 1. Data of the illustration

\begin{tabular}{lllll}
\hline & Input & & Output & \\
DMU & $-\mathrm{X}_{1}$ & $\mathrm{X}_{2}$ & $\mathrm{Y}_{1}$ & $\mathrm{Y}_{2}$ \\
\hline A & 31 & 42 & 74 & 45 \\
B & 23 & 34 & 42 & 25 \\
C & 26 & 45 & 32 & 65 \\
D & 36 & 61 & 66 & 35 \\
E & 18 & 76 & 43 & 55 \\
\hline
\end{tabular}

The optimal solution to Equation (9) is: $\alpha=0.3814, \beta$ $=0.0, \theta^{*}=(1+\beta) /(1-\alpha)=1.6166$.

\section{DISCUSSION}

Efficiency Evaluation of the Dominated Decision Making Units: It is indicated from solution of nonoriented mode that when $\alpha=\beta=0.0$, the efficiency value of DMU is " 1 " under the non-oriented mode of SE-BCC. If none of the output variables of $\mathrm{DMU}_{\mathrm{k}}$ in a certain unit are greater than those of another unit and none of the input variables of $\mathrm{DMU}_{\mathrm{k}}$ are smaller than those of $\mathrm{DMU}_{\mathrm{j}}$, then in Equation (6) $\alpha=\beta=0.0$. To specify the relationships involved, we thus give the following definitions: When none of the output variables $y_{\mathrm{rk}}$ in $\mathrm{DMU}_{\mathrm{k}}$ are greater than $\left\{\mathrm{y}_{\mathrm{rj}}\right\}$ (i.e., $\left.\mathrm{y}_{\mathrm{rk}} \leqq\left\{\mathrm{y}_{\mathrm{rj}}\right\}\right)$ and also when $\mathrm{x}_{\mathrm{ik}} \leqq\left\{\mathrm{x}_{\mathrm{ij}}\right\}, \mathrm{j}=1, \ldots, \mathrm{n}, \mathrm{j} \neq \mathrm{k}$, then $\mathrm{DMU}_{\mathrm{k}}$ is called "dominated decision making units".

Since there must be a lot of dominated decision making units among DMU, the adoption of Equation (3) (Cheng et al., 2011) or Equation (6) of the present study will definitely result in another shortcoming of "low discrimination". As the problem of infeasible solution in SE-BCC model does not necessarily exist, the present study thus suggests not to employ non-oriented mode to the efficiency evaluation of dominated decision making units. Though there will be two evaluation criteria in a system, the study claims that when in relative efficiency assessment, rank ordering of efficiency is more important than mere efficiency values and efficiency is of comparative nature.

Through the discussion in this study, we conceive that there should be different solutions to the problem of infeasible solution in SE-BCC mode. To take the data of individual DMU as example:

- $\mathrm{y}_{\mathrm{a} 1}$ of $\mathrm{DMU}_{\mathrm{a}}>\left\{\mathrm{y}_{\mathrm{b} 1}, \mathrm{y}_{\mathrm{c} 1}, \mathrm{y}_{\mathrm{d} 1}, \mathrm{y}_{\mathrm{e} 1}\right\} ; \mathrm{y}_{\mathrm{c} 2}$ of $\mathrm{DMU}_{\mathrm{c}}>\left\{\mathrm{y}_{\mathrm{a} 2}\right.$, $\left.\mathrm{y}_{\mathrm{b} 2}, \mathrm{y}_{\mathrm{d} 2}, \mathrm{y}_{\mathrm{e} 2}\right\}$, thus, $\mathrm{DMU}_{\mathrm{a}}$ and $\mathrm{DMU}_{\mathrm{c}}$ fit in "inputoriented", "output-oriented" and "non-oriented mode"

- $\mathrm{X}_{\mathrm{e} 1}$ of $\mathrm{DMU}_{\mathrm{e}}<\left\{\mathrm{X}_{\mathrm{a} 1}, \mathrm{X}_{\mathrm{b} 1}, \mathrm{X}_{\mathrm{cl}}, \mathrm{X}_{\mathrm{d} 1}\right\} \quad \mathrm{xb}_{2} ;$ of $\mathrm{DMU}_{\mathrm{b}}<\left\{\mathrm{X}_{\mathrm{a} 2}, \mathrm{X}_{\mathrm{c} 2}, \mathrm{X}_{\mathrm{d} 2}, \mathrm{X}_{\mathrm{e} 2}\right\}$, thus, $\mathrm{DUM}_{\mathrm{e}}$ and $\mathrm{DMU}_{\mathrm{b}}$ fit it "input-oriented", "output-oriented" and "nonoriented mode"
- $\mathrm{DMU}_{\mathrm{d}}$ dominated by $\mathrm{DMU}_{\mathrm{a}}$, thus these two DMU do not fit in "non-oriented mode"

\section{CONCLUSION}

The A-P super efficiency model in DEA contributes greatly to enhancing level of discrimination. Such a powerful tool for efficiency evaluation often comes with infeasible solution under the conditions of variable returns to scale and a large number of scholars have been striving for finding solutions to the problem of infeasible solution. The present study revises the model of Cheng et al. (2011) by transforming their non-linear mode into linear mode, as well as providing a proof of the reasonable efficient value of $\mathrm{DMU}_{\mathrm{k}}$, through the use of a theorem. Also in this study, an example is given to delineate the application with extensive adoption of the improved SEBCC model; that is, Dominated Decision Making Units is defined and the efficiency value is " 1 " under nonoriented conditions. In order not to lower discrimination level of efficiency evaluation, the study suggests that non-oriented model not be adopted.

\section{REFERENCES}

Andersen, P. and N.C. Petersen, 1993. A procedure for ranking efficient units in data envelopment analysis. Manage. Sci., 39: 1261-1265. DOI: 10.1287/mnsc.39.10. 1261

Banker, R.D. and H. Chang, 2005. The super-efficiency procedure for outlier identification, not for ranking efficient units. Eur. J. Operat. Res., 175: 1311-1320. DOI: 10.1016/j.ejor.2005.06.028

Charnes, A., S. Haag. P. Jaskaa and J. Semple, 1992. Sensitivity of efficiency classifications in the additive model of data envelopment analysis. Int. J. Syst. Sci., 23: 789-798. DOI: 10.1080/00207729208949248

Charnes, A., W.W. Cooper and E. Rhodes, 1978. Measuring the efficiency of decision making units. Eur. J. Operat. Res., 2: 429-444. DOI: 10.1016/0377-2217(78)90138-8

Chen, Y., 2005. Measuring super-efficiency in DEA in the presence of infeasibility. Eur. J. Operat. Res., 161: 545-551. DOI: 10.1016/j.ejor.2003.08.060

Cheng, G., Z. Qian and P.D. Zervopoulos, 2011. Overcoming the infeasibility of super-efficiency DEA model: A model with generalized orientation. MPRA. 
Ebadi, S., 2012. Using a Super Efficiency Model for Ranking units in DEA. Applied Math. Sci., 41: 2043-2048.

Leopold, S., 2003. Detecting outliers in frontier models: A simple approach. J. Product. Anal., 20: 391-424. DOI: 10.1023/A:1027308001925

Pan, S.C., S.Y. Liu, C.J. Peng and P.C. Wu, 2011. Local government efficiency evaluation: Consideration of undesirable outputs and super-efficiency. Afr. J. Bus. Manage., 5: 4746-4758.

Ray, S.C., 2008. The directional distance function and measurement of super-efficiency: An application to airlines data. Eur. J. Operat. Res., 59: 788-797. DOI: 10.1057/palgrave.jors. 2602392

Seiford, L.M. and J. Zhu, 1998. Sensitivity analysis of DEA models for simultaneous changes in all the data. J. Operat. Res. Society, 49: 1060-1071.
Seiford, L.M. and J. Zhu, 1999. Sensitivity and stability of the classifications of returns to scale in data envelopment analysis. J. Product. Anal., 12: 55-75. DOI: 10.1023/A:1007803207538

Thrall, R.M., 1996. Duality, classification and slacks in DEA. Annals Operat. Res., 66: 109-138. DOI: 10.1007/BF02187297

Xue, M. and P.T. Harker, 2002. Note: Ranking DMUs with infeasible super-efficiency DEA models. Manage. Sci., 48: 705-710. DOI: $10.1287 / \mathrm{mnsc}$.48.5.705.7805

Zhu, J., 1996. Robustness of the efficient DMUs in data envelopment analysis. Eur. J. Operat. Res., 90: 451460. DOI: 10.1016/0377-2217(95)00054-2

Zhu, J., 2001. Super-Efficiency and DEA sensitivity analysis. Eur. J. Operat. Res., 129: 443-455. DOI: 10.1016/S0377-2217(99)00433-6 